\title{
Pineapple Peel-Derived Carbon Dots: Applications as Sensor, Molecular Keypad Lock, and Memory Device
}

\author{
Somasundaram Anbu Anjugam Vandarkuzhali, ${ }^{\dagger}$ Sampathkumar Natarajan, ${ }^{\S}$ Shanmugapriya Jeyabalan, ${ }^{\prime \prime}$
}

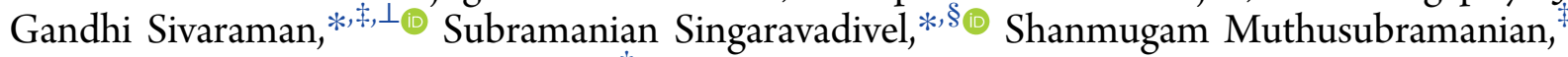
and Balasubramanian Viswanathan ${ }^{* \dagger}$

${ }^{\dagger}$ National Centre for Catalysis Research, Indian Institute of Technology Madras, Chennai 600036, India

${ }^{\ddagger}$ School of Chemistry, Madurai Kamaraj University, Madurai 625021, India

${ }^{\S}$ Department of Chemistry, SSM Institute of Engineering and Technology, Dindigul 624002, India

"Department of Chemistry, Thiagarajar College of Engineering, Madurai 625018, India

${ }^{\perp}$ Department of Chemistry, Gandhigram Rural Institute-Deemed to be University, Gandhigram, Dindigul 624302, India

\section{Supporting Information}

ABSTRACT: Herein, the fluorescent carbon dots (CDs) with blue emission were prepared by hydrothermal treatment using pineapple peel as a source of carbon. The as-prepared CDs exhibited turn-Off fluorescence behavior toward $\mathrm{Hg}^{2+}$ and subsequent turn-On behavior for L-cysteine along with enhanced biocompatibility and negligible cytotoxicity for cell imaging. The practical applicability of carbon dots was used for the quantification of $\mathrm{Hg}^{2+}$ in water. On the basis of the spectral characteristic changes, we have designed individual elementary logic operations such as NOT and IMP gates, by utilizing CD as probe and $\mathrm{Hg}^{2+}$ and $\mathrm{L}-\mathrm{Cys}$ as chemical inputs. We have also demonstrated the utility of this system in electronic security devices and as memory element, with the idea of the switching.

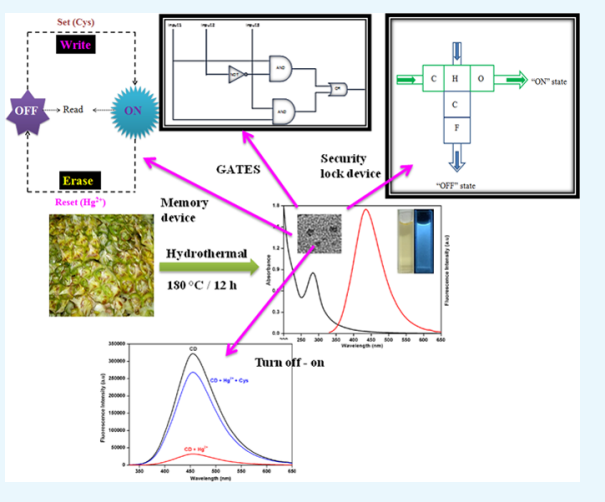

\section{INTRODUCTION}

Carbon dots (CDs), a new member of fluorescent nanosized carbon materials, with sizes of less than $10 \mathrm{~nm}$, have received increased attention of many researchers because of their superior resistance to photobleaching, increased chemical- and photostability, least toxicity, low cost, and abundant availability as raw materials in nature. ${ }^{1}$ The recent developments of CDs were due to their promising applications in biological imaging, ${ }^{2}$ sensor materials, ${ }^{3}$ drug carriers, ${ }^{4}$ photocatalysts, ${ }^{5}$ and photothermal therapy. ${ }^{6}$ Much efforts have been focused on the facile synthesis of CDs by electrochemical method, thermal method, hydrothermal method, acidic oxidation, microwave, ultrasonic treatment, and laser ablation. ${ }^{7}$ More recently, hydrothermal treatment was used because of low cost and nontoxic routes for producing novel carbon materials; it involves dehydration followed by in situ surface passivation.

CDs obtained from different natural resources have been reported from small molecules to wastes, vegetables, and fruits. $^{8-11}$ Mostly, carbon dots have least solubility in water and this has limited their analytical applications. ${ }^{12}$ Pineapple peel is widely produced during the processing of pineapple to get juices and salads. ${ }^{13}$ The main contents of the pineapple peel are cellulose, hemicellulose, lignin, and pectin, in which cellulose occupies $20-25 \%$ of the dry weight. ${ }^{14} \mathrm{Hg}^{2+}$ is the most dangerous inorganic pollutant and causes environmental and health concerns. ${ }^{15}$ Mercury exposure may lead to digestive, renal, and neurological diseases. ${ }^{16}$ Due to these adverse effects of $\mathrm{Hg}^{2+}$ ions, there is an urgent need to develop a convenient and rapid method to detect $\mathrm{Hg}^{2+} \cdot{ }^{17}$ Herein, in this study, pineapple peel was chosen as a precursor to prepare CDs. The CDs were successfully applied as a fluorescence probe for cell imaging and sensitive detection of $\mathrm{Hg}^{2+}$ in living cells, and also applications as a molecular keypad lock and memory device have been reported.

\section{RESULTS AND DISCUSSIONS}

The CDs were prepared by simple hydrothermal treatment of pineapple peel as precursor. The main constituents of pineapple peel were cellulose $(40-46 \%)$, hemicellulose (16-20\%), lignin $(12-16 \%)$, and pectin $(8-12 \%){ }^{18}$ The resultant CDs exhibited excellent water solubility and a blue color under a UV lamp (365 $\mathrm{nm}$ ), illustrating that the carbon dots are showing strong blue fluorescence. The quantum yield of the CDs (quinine sulfate in $0.1 \mathrm{~mol} \mathrm{~L}^{-1} \mathrm{H}_{2} \mathrm{SO}_{4}$, excited at $340 \mathrm{~nm}$ ) was about $42 \%$ (Figure S1, Supporting Information), which is much higher than that in previous reports. ${ }^{9 \mathrm{~d}, 10 \mathrm{a}-\mathrm{c}}$

Received: May 26, 2018

Accepted: September 25, 2018

Published: October 4, 2018 

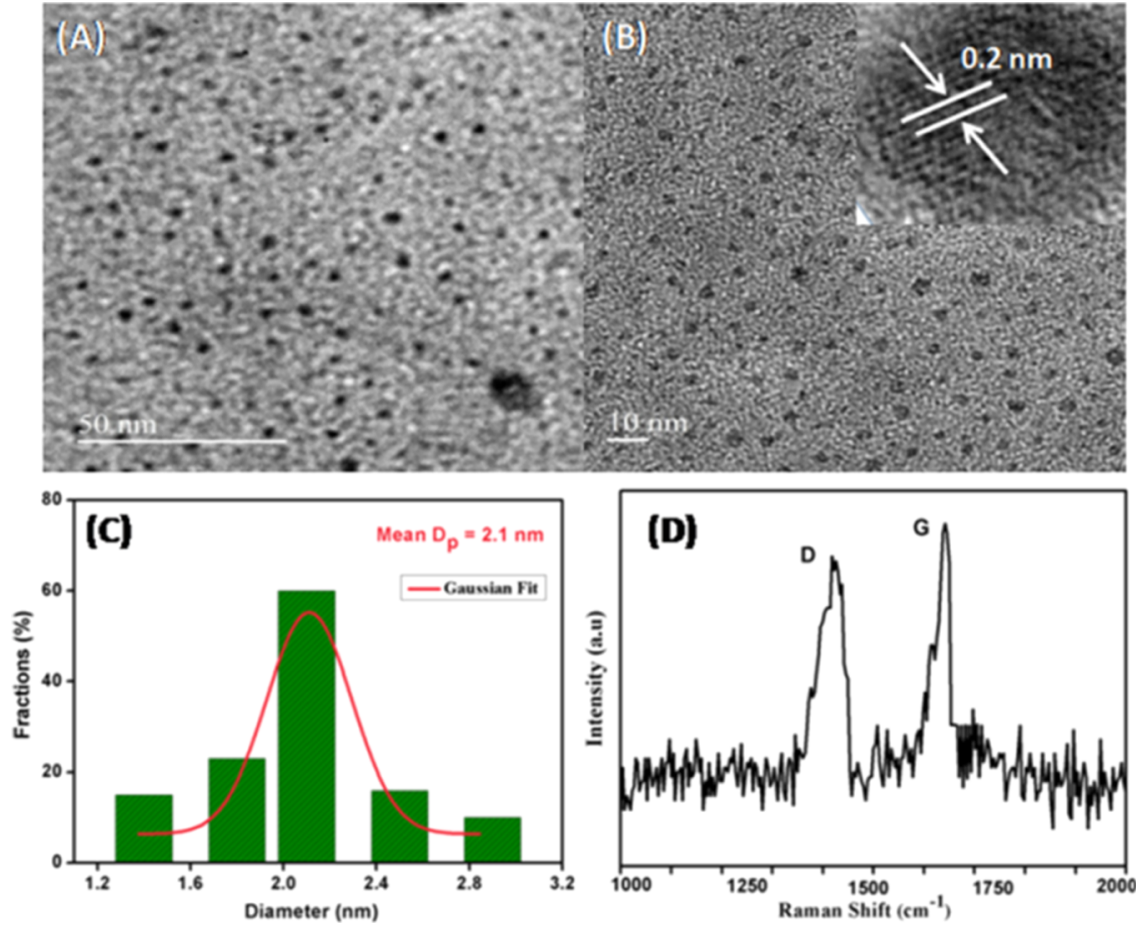

Figure 1. (A, B) HRTEM images (inset lattice fringe); (C) particle size distribution from HRTEM; (D) Raman spectra of CDs.
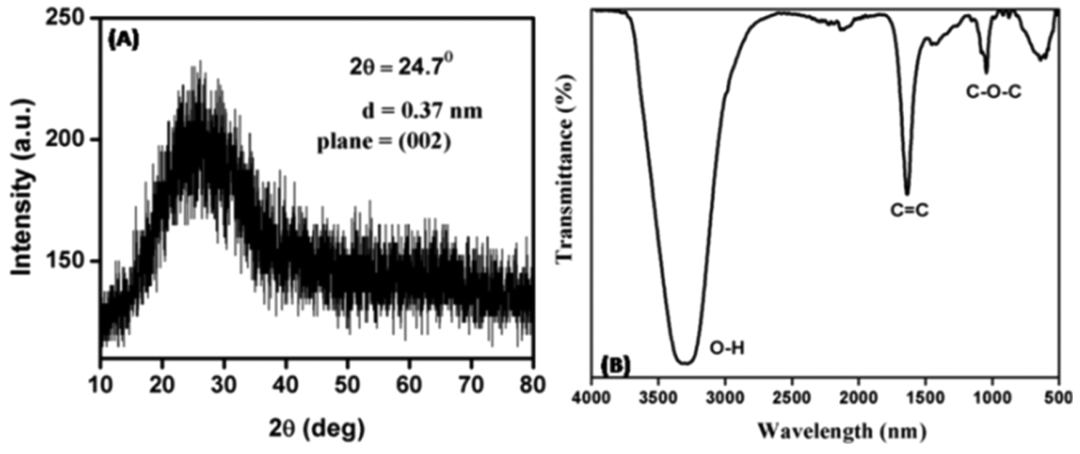

Figure 2. (A) XRD pattern; (B) FT-IR spectra of CDs.
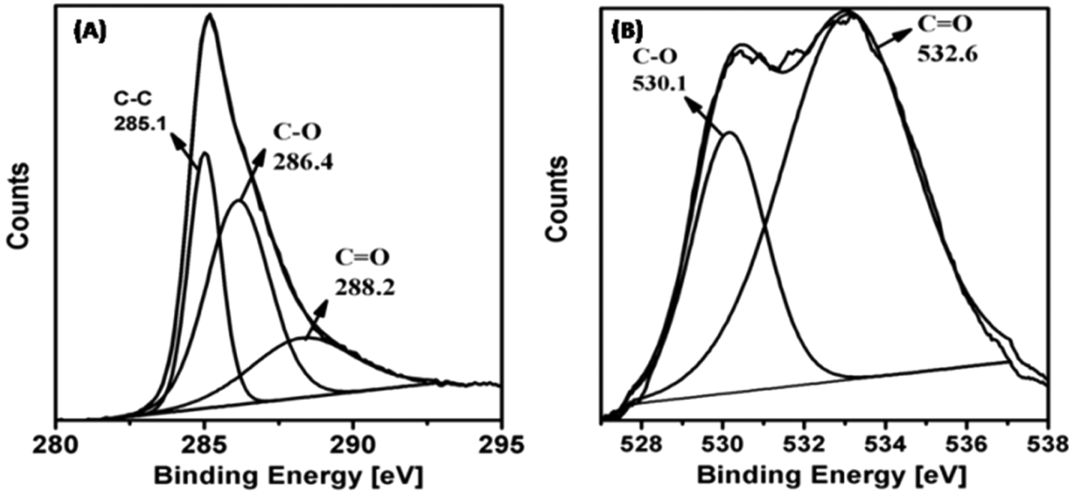

Figure 3. High-resolution XPS spectra of (A) C 1s and (B) O 1s.

The dimension and morphology of the CDs observed under high-resolution transmission electron microscopy (HRTEM), as shown in Figure 1A, clearly demonstrate unvarying and monodisperse nature of the CDs. HRTEM image (Figure 1B inset) shows lattice fringes with an interplanar spacing of 0.20 $\mathrm{nm}$, which is close to the (102) facet of graphite. ${ }^{10 \mathrm{a}}$ The particle size distribution (Figure 1C) of CDs displays the size distribution as mainly between 2 and $3 \mathrm{~nm}$. Raman spectra of CDs (Figure 1D) showed the bands at 1374 and $1589 \mathrm{~cm}^{-1}$ for the structure of polyaromatic $\mathrm{sp}^{2}$-hybrid carbon network in twodimensional hexagonal lattice of a graphite cluster. ${ }^{19}$ 

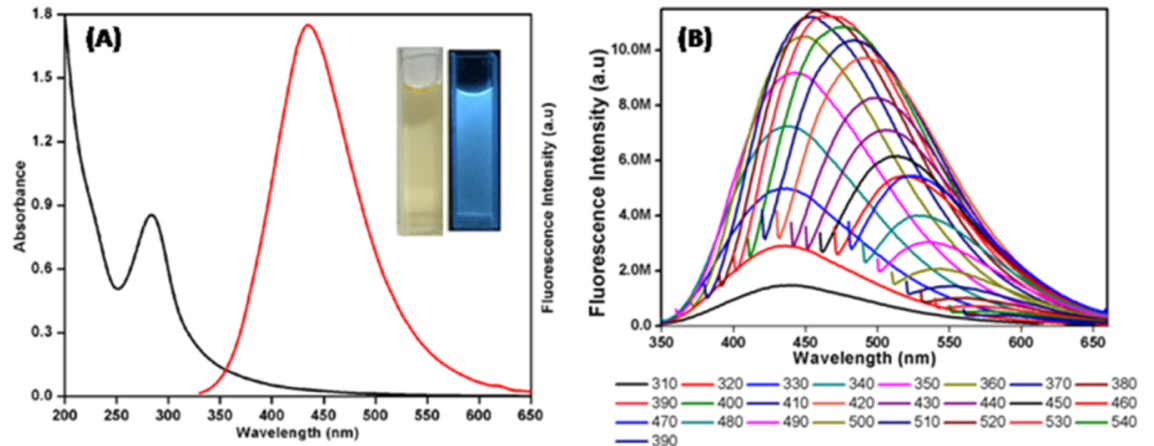

Figure 4. (A) UV-vis absorption, photoluminescence (PL) excitation, and emission spectra and (inset) images of the CDs under room light (left) and UV light (right) in an aqueous solution. (B) Excitation-dependent PL spectra of the CDs in an aqueous solution.
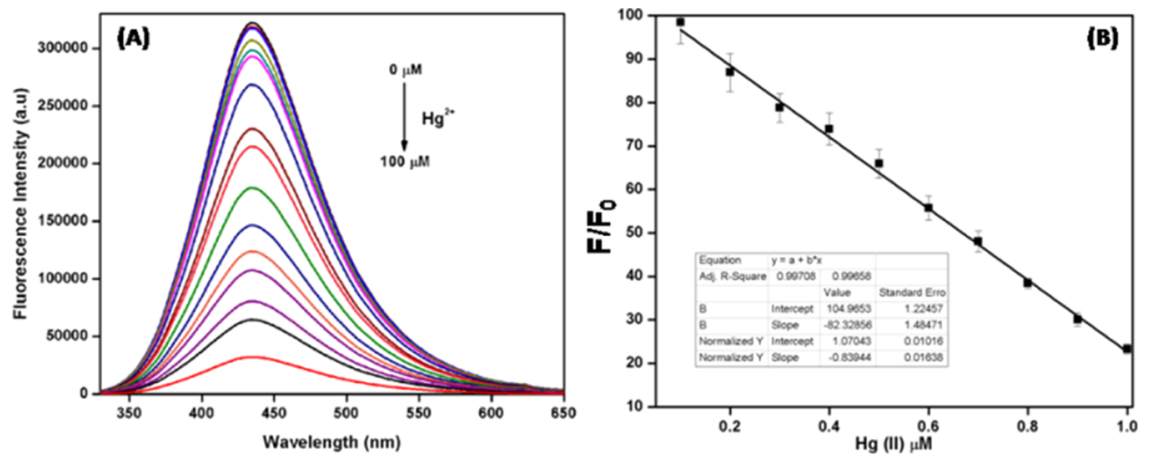

Figure 5. (A) Titrimetric quenching pattern of the fluorescence intensity of $\mathrm{CD}\left(1 \mathrm{mg} \mathrm{mL}{ }^{-1}\right)$ in phosphate-buffered saline solution (pH 7.4) after addition of $\mathrm{Hg}^{2+}$ ion; (B) Stern-Volmer fitting.

The X-ray diffraction (XRD) pattern of as-prepared CDs in Figure $2 \mathrm{~A}$ revealed a broad diffraction peak centered at $2 \theta=$ $24.7^{\circ}$, which is attributed to crystalline graphite $\left(\mathrm{sp}^{2}\right.$ hybridization). Generally, Fourier transform infrared (FT-IR) spectrum is used to identify the surface functional groups of CDs. The CDs exhibited a broad peak at $\sim 3315 \mathrm{~cm}^{-1}$, which is characteristic of the stretching vibrations of $-\mathrm{OH}$. The peaks centered at 1634 and $1040 \mathrm{~cm}^{-1}$ were ascribed to the stretching vibration of $\mathrm{C}=\mathrm{C}$ and $\mathrm{C}-\mathrm{O}-\mathrm{C}$ respectively, indicating the presence of $\operatorname{sp}^{2}$ (Figure $2 \mathrm{~B}$ ).

To get an insight into the elemental composition and chemical bonds of the prepared carbon dots, X-ray photoelectron spectroscopy (XPS) measurements are carried out. The high-resolution XPS spectra for $\mathrm{C} 1 \mathrm{~s}$ are divided into three unit moieties, with the binding energy being 284.1, 285.7, and 288.3 $\mathrm{eV}$ (Figure $3 \mathrm{~A}$ ). They are assigned as $\mathrm{C}=\mathrm{C} / \mathrm{C}-\mathrm{C}, \mathrm{C}-\mathrm{OH} / \mathrm{C}-$ $\mathrm{O}-\mathrm{C}$, and $\mathrm{O}-\mathrm{C}=\mathrm{O}$, respectively. ${ }^{9}$ Similarly deconvoluted $\mathrm{O} 1 \mathrm{~s}$ (Figure $3 \mathrm{~B}$ ) peaks centered at 530.6 and 532.1 correspond to the $\mathrm{C}=\mathrm{O}$ and $\mathrm{C}-\mathrm{OH}$ groups, respectively. ${ }^{21}$ The presence of these $\mathrm{C}=\mathrm{O}$ and $\mathrm{C}-\mathrm{OH}$ groups suggests that these hydrophilic moieties facilitate CDs to disperse in aqueous solution. The photophysical properties of the CDs were investigated by UVvis and fluorescence spectroscopy. The characteristic absorption peak at $280 \mathrm{~nm}$ is assigned to the $\pi-\pi^{*}$ transition of $\mathrm{C}=\mathrm{C}$, as observed from the CDs prepared by the carbonization of carbonbased materials. ${ }^{8 \mathrm{~d}, 10 \mathrm{a}}$ As illustrated in the insets of Figure 4A, the solution color of CDs is yellow under visible light (left), whereas a blue emission is observed upon exciting with UV light of 365 nm (right).

Figure 4B demonstrates the optical properties of CDs, i.e., excitation-dependent PL behavior. Upon changing the excitation wavelength, the peak is red-shifted and the peak intensity decreases due to different surface sites and particle size. The fluorescence intensities remain constant at high salt concentrations (up to $1000 \mathrm{mM}$ ), showing high stability of the CDs even under high ionic strength conditions and also showing maximum intensity at physiological $\mathrm{pH}$ (Figures S2 and S3, Supporting Information). This might be due to the protonation and deprotonation of the surface oxygeneous groups in acidic and basic environment, which agrees with earlier reports. ${ }^{19,20}$ To determine whether these might affect measurement of CDs, interference experiments were conducted on common metal ions in the presence of the CDs $(0.1 \mathrm{mg}$ $\mathrm{mL}^{-1}$, Figure S4, Supporting Information). The fluorescence response of $\mathrm{CDs}$ was examined under identical conditions by treatment of $0.1 \mathrm{mg} \mathrm{mL}^{-1} \mathrm{CD}$ solution with $50 \mu \mathrm{M} \mathrm{Ag}^{+}, \mathrm{Al}^{3+}$, $\mathrm{Co}^{2+}, \mathrm{Cd}^{2+}, \mathrm{Cr}^{3+}, \mathrm{Cu}^{2+}, \mathrm{Ca}^{2+}, \mathrm{Fe}^{2+}, \mathrm{Fe}^{3+} \mathrm{Pb}^{2+}, \mathrm{Mn}^{2+}, \mathrm{Mg}^{2+}, \mathrm{Ni}^{2+}$, $\mathrm{Zn}^{2+}$, and $\mathrm{Hg}^{2+}$ ions. Figure 5A shows a gradual decrease in fluorescence intensity with increasing concentration of $\mathrm{Hg}^{2+}$.

We checked the interference of other metal ions by competitive binding, such as $\mathrm{Ag}^{+}, \mathrm{Al}^{3+}, \mathrm{Co}^{2+}, \mathrm{Cd}^{2+}, \mathrm{Cr}^{3+}, \mathrm{Cu}^{2+}$, $\mathrm{Ca}^{2+}, \mathrm{Fe}^{2+}, \mathrm{Fe}^{3+}, \mathrm{Pb}^{2+}, \mathrm{Mn}^{2+}, \mathrm{Mg}^{2+}, \mathrm{Ni}^{2+}$, and $\mathrm{Zn}^{2+}$, toward $\mathrm{Hg}^{2+}$ sensing by CDs; it is found that there is no interference for $\mathrm{Hg}^{2+}$ sensing. The fluorescence quenching of CDs upon addition of $\mathrm{Hg}^{2+}$ ions may be attributed to the excited-state electron-transfer reaction of the CDs to the $\mathrm{Hg}^{2+}$ ion. ${ }^{21}$ As shown in Figure 5B, the Stern-Volmer plot shows linearity in the concentration range of $0.1-100 \mu \mathrm{M}$, yielding a $K_{\mathrm{SV}}$ of $2.2 \times 10^{4} \mathrm{M}^{-1}$. The detection limit is estimated to be $4.5 \mathrm{nM}$. The reversibility of the $\mathrm{CD}-\mathrm{Hg}^{2+}$ complex been investigated by adding amino acids.

The emission spectra of $\mathrm{CD}-\mathrm{Hg}^{2+}$ complex with various amino acids, such as alanine (Ala), lysine (Lys), aspartic acid (Asp), arginine (Arg), methionine (Met), proline (Pro), threonine (Thr), tryptophan (Trp), histidine (His), valine 
(Val), phenylalanine (Phe), serine (Ser), and L-cysteine (Cys), were recorded (Figure S5, Supporting Information). ${ }^{10 \mathrm{e}}$ The results clearly indicate that other amino acids except cysteine do not show any fluorescence changes, i.e., the intensity of fluorescence remained constant. However, addition of L-Cys resulted in the enhancement of emission intensity. The limit of detection of $\mathrm{CDs} / \mathrm{Hg}^{2+}$ ensembles with $\mathrm{L}$-Cys was calculated to be $8.7 \times 10^{-7} \mathrm{M}$ on $3 \sigma / \mathrm{s}$. However, a decrease in the excitedstate lifetime after the $\mathrm{Hg}^{2+}$ complex formation confirms that the quenching process is dynamic in nature. Figure 6 shows the excited-state lifetime in the absence and presence of $\mathrm{Hg}^{2+}$ ions.

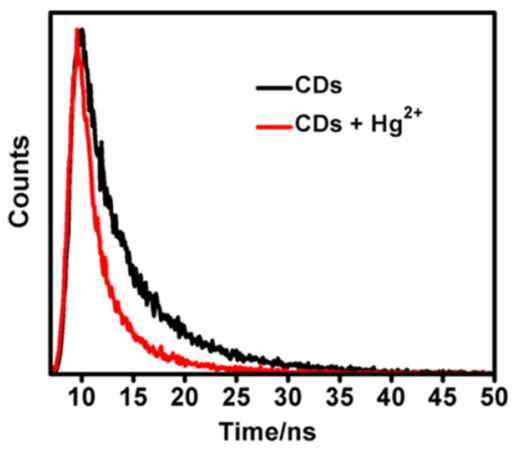

Figure 6. Lifetime data of only CDs and with $\mathrm{Hg}^{2+}\left(\lambda_{\mathrm{ex}}=320 \mathrm{~nm} ; \lambda_{\mathrm{em}}=\right.$ $435 \mathrm{~nm})$.

The lifetime quenches from $2.95 \mathrm{~ns}\left(\tau_{1}=2.38, \tau_{2}=0.57\right)$ to $2.51 \mathrm{~ns}\left(\tau_{1}=2.22, \tau_{2}=0.29\right)$ upon addition of $\mathrm{Hg}^{2+}$. The significant reduction in the lifetime value indicates that the quenching process is dynamic in nature and takes place via an excited-state electron-transfer reaction. ${ }^{19 a}$

The Stern-Volmer constant $\left(K_{\mathrm{SV}}\right.$ of $\left.2.2 \times 10^{4} \mathrm{M}^{-1}\right)$ suggests the dynamic quenching of fluorescence on the addition of $\mathrm{Hg}^{2+}$ to CDs; this dynamic quenching by ultrafast electron transfer from $\mathrm{Hg}^{2+}$ to CDs is further confirmed by fluorescence lifetime measurements. Hence, the $\mathrm{Hg}^{2+}$-induced quenching of CDs is due to electron transfer from $\mathrm{Hg}^{2+}$ to $\mathrm{CDs}$. The sensing properties of CDs toward $\mathrm{Hg}^{2+}$ are reproducible; we carried out the addition of ethylenediaminetetraacetic acid to $\mathrm{CD}-\mathrm{Hg}^{2+}$ system to check their reproducibility; it is noticed that even after five cycles, the CDs are able to sense $\mathrm{Hg}^{2+}$, indicating that the $\mathrm{CD}$ sensing performance is reproducible. We studied the temperature dependency to the fluorescence of CDs with varying temperature; it is observed that increase in temperature leads to decrease in fluorescence intensity.

The exciting photophysical properties, such as high sensitivity, selectivity, and fast response, of CDs with $\mathrm{Hg}^{2+}$ prompted us to investigate their potential use in real-time monitoring of $\mathrm{Hg}^{2+}$ ions in living cells via fluorescence imaging. It is well known that apart from being toxic, $\mathrm{Hg}^{2+}$ ion has a tendency to bind with estrogen receptors in breast cancer cells, causing amplified cell growth and estrogenic effects, such as irregular menstruation, reproductive tract, the urinary tract disorders, and formation of abnormal secondary sexual characteristics like armpit hair and neural disorders. Hence, the recognition of the mercury ions in these cells is a challenge.

To demonstrate the possible cellular toxicity of CDs toward HeLa and MCF-7 cells, the 3-(4,5-dimethylthiazol-2-yl)-2,5diphenyltetrazolium bromide assay was carried out. The cell viabilities were calculated upon exposure of different concentrations to the carbon dots (Figure S6 Supporting Information), which revealed that the CDs exhibited extremely low cytotoxicity, i.e., viability of about $92 \%$ at a concentration of $0.5 \mathrm{mg} \mathrm{mL}^{-1}$ after $24 \mathrm{~h}$ incubation, and viability over $84 \%$ even high concentration $\left(1 \mathrm{mg} \mathrm{mL}^{-1}\right)$.

HeLa cells incubated with carbon dots and imaged through the fluorescence microscope show distinct fluorescence inside the cells, confirming the cellular uptake of CDs (Figure 7). The cells treated with CDs were incubated with $\mathrm{Hg}^{2+}$ ions for $10 \mathrm{~min}$. The results showed that $\mathrm{Hg}^{2+}$ reduces the intensity of the fluorescence of CDs in biological systems, also thereby making

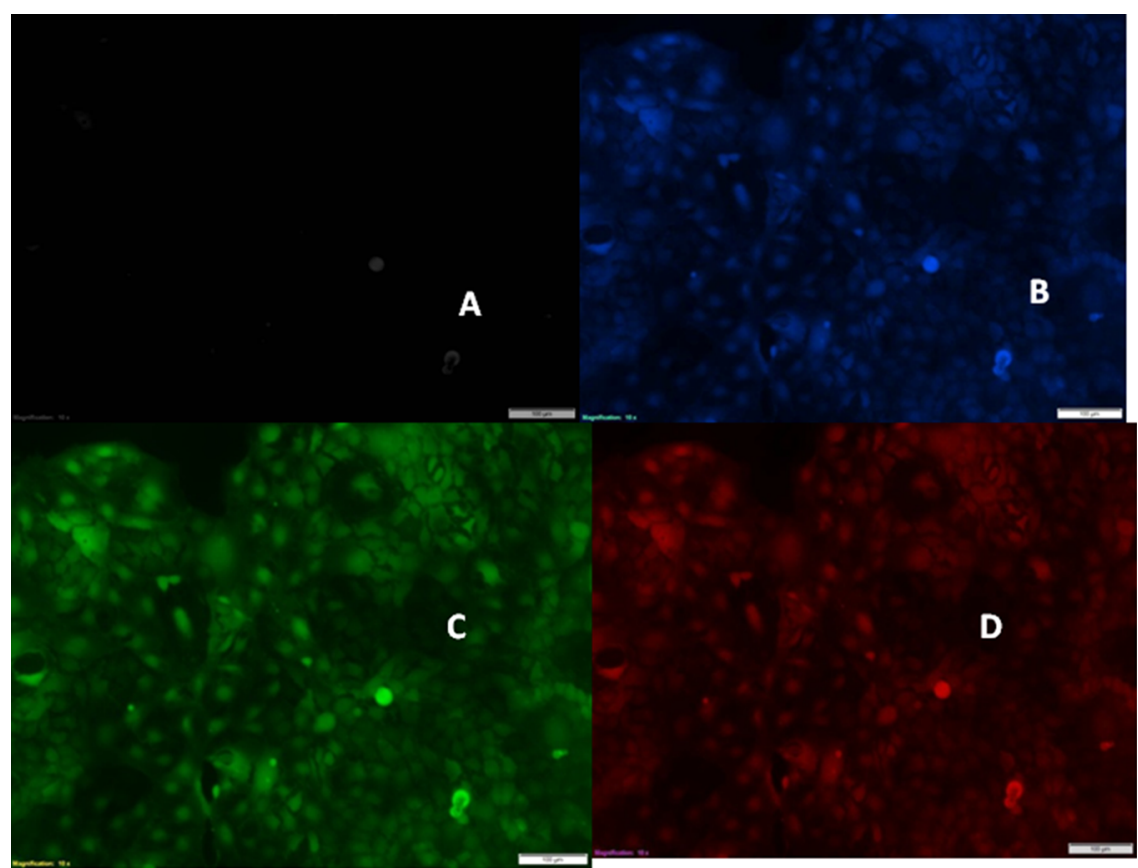

Figure 7. Fluorescence microscopic imaging of HeLa cells: (A-D) $0.50 \mathrm{mg} \mathrm{mL}^{-1} \mathrm{CDs}$ at $37^{\circ} \mathrm{C}$ for a $3 \mathrm{~h}$ excitation by $408 \mathrm{~nm}(\mathrm{~B}), 488 \mathrm{~nm},(\mathrm{C})$ and $561 \mathrm{~nm}$ (D) and bright-field images (A). The scale bar indicates $20 \mu \mathrm{m}$. 


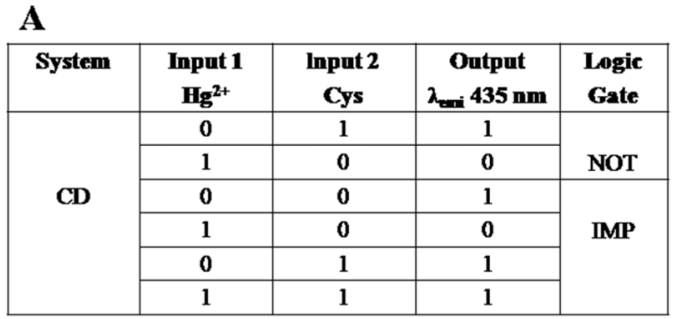

$\mathbf{C}$

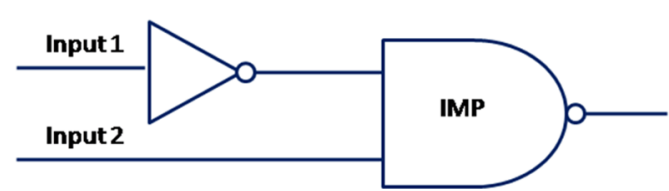

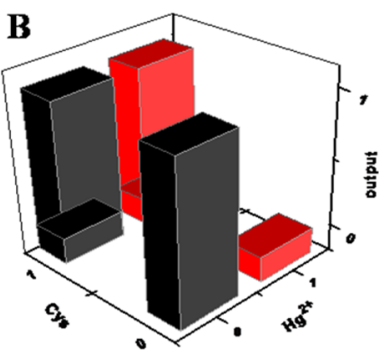$$
\text { . }
$$

d IMP gates, respectively,
dical inputs $\mathrm{Hg}^{2+}$ and L-Cys.

Figure 8. (A) Truth table for one and two strings and its corresponding digital input and output signals represent NOT and IMP gates, respectively,
(B) bar diagram representing the two-input system, (C) schematic representation of logic functions of CD with two chemical inputs $\mathrm{Hg}^{2+}$ and $\mathrm{L}-\mathrm{Cys}$.

Scheme 1. Schematic Representation of Binary Logic Gates for CD System with $\mathrm{Hg}^{2+}$ and $\mathrm{CD}-\mathrm{Hg}^{2+}+\mathrm{L}-\mathrm{Cys}$ Representing NOT and IMP Gates

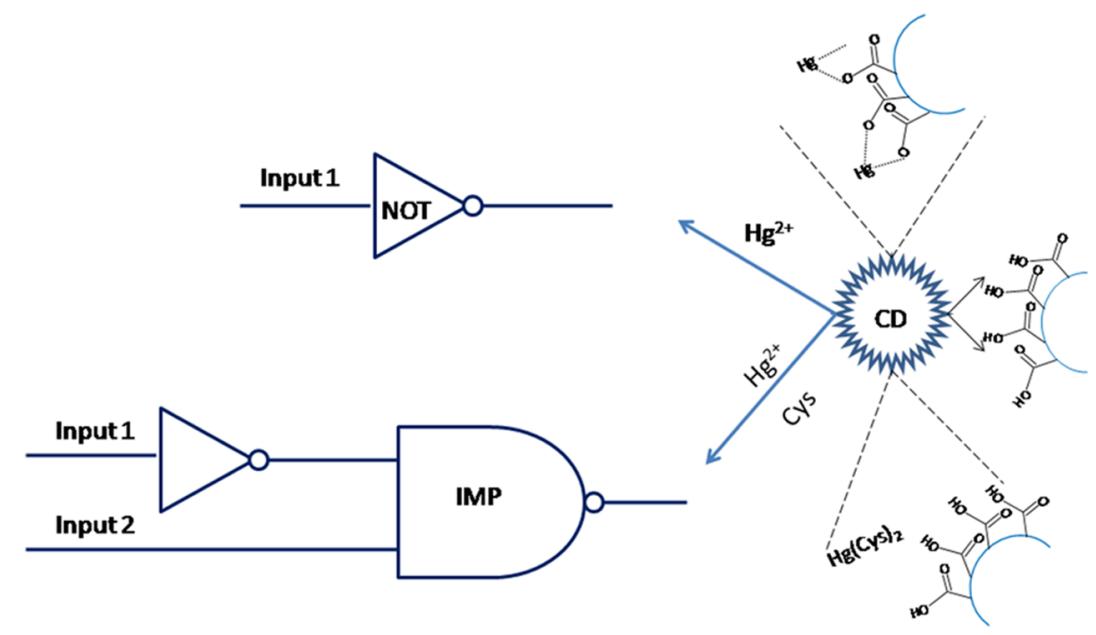

CDs as efficient probe for intracellular $\mathrm{Hg}^{2+}$ detection. The bright-field image of cells treated with carbon dots and $\mathrm{Hg}^{2+}$ inveterate that the cells were viable throughout the experimental conditions. This observation established that the CDs could act as a potential candidate for the intracellular detection of $\mathrm{Hg}^{2+}$.

Turn-On fluorescence and selective sensing of L-Cys among all other amino acids by $\mathrm{CDs}-\mathrm{Hg}^{2+}$ ensemble encouraged us to explore its use for the cellular imaging of L-cysteine in living fibroblasts (Figure S9) and HeLa cells (Figure S7, Supporting Information). The cells were incubated with $\mathrm{CD}-\mathrm{Hg}^{2+}$ ensemble $(10 \mu \mathrm{M})$ for $10 \mathrm{~min}$ and the $\mathrm{CD}-\mathrm{Hg}^{2+}$ added cells were washed with buffer before imaging through confocal fluorescence microscopy. Very bright blue fluorescence from the inside of the cells was observed, showing the presence of intracellular biothiols, as shown in Figure S9B. Another set of cells was pretreated with a known biothiol quencher $\mathrm{N}$ ethylmaleimide (NEM) in culture media. The NEM pretreated cells are incubated with $\mathrm{CD}-\mathrm{Hg}^{2+}$ ensemble. The cells did not exhibit any observable fluorescence changes, as shown in Figure S9C. This proved the $\mathrm{CD}-\mathrm{Hg}^{2+}$ is permeable to cell wall and the resulted changes account for the changes in the intracellular thiol level. The bright-field images confirmed that the cells were viable throughout the experiments. These results provided a way to monitor the changes of $\mathrm{L}$-cysteine levels in the living cells. To ensure the intrusion of glutathione (GSH) during cysteine detection in living cells, we intend to verify whether the fluorescence increase is due to cys or GSH. We used an inhibitor for GSH synthesis L-buthionine sulfoximine (BSO) assay. BSOtreated cells were imaged, showing the increase in fluorescence when compared with the control that is untreated with BSO. On the other hand, when the cells were treated with $\mathrm{BSO}+\mathrm{H}_{2} \mathrm{O}_{2}$, they showed decrease in fluorescence intensity (Figure S8, Supporting Information). Further, confocal images of the BSO + $\mathrm{H}_{2} \mathrm{O}_{2}$-treated cells on treatment with $\mathrm{N}$-acetyl cysteine (a precursor for Cys), showed a dramatic increase in fluorescence intensity, obviously indicating that the fluorescence enhancement is exclusively due to changes in intracellular cysteine rather than intracellular GSH. ${ }^{10}$

Design of the Logic Gate. Designing logic gates utilizing electronic circuits in nanoregime is essential in molecular computation. Molecular logic gates mimic electronic circuits by performing Boolean arithmetic operations in the form of physicochemical and biological changes as their inputs. This type of logic gate was fabricated using the fluorescence response of the probe used with the different analytes on the basis of the consequent changes in the fluorescence intensity of the probe.

On the basis of the spectral characteristic changes, we have designed individual elementary logic operations, such as NOT 

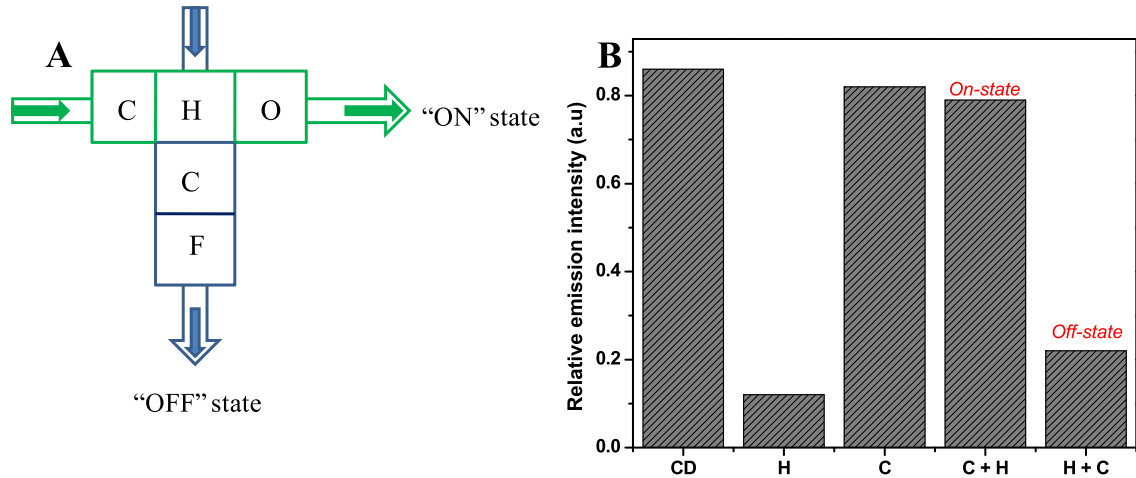

Figure 9. (A) Schematic representation of a keypad security lock model using $\mathrm{CD}$ as the molecular fluorescence system; (B) bar diagram representing the change in the emission intensity of $\mathrm{CD}$. Chemical inputs were represented as $\mathrm{H}$ and $\mathrm{C}$ for $\mathrm{Hg}^{2+}$ and $\mathrm{L}-\mathrm{Cys}$ and $\mathrm{O}$ and $\mathrm{F}$ for On and $\mathrm{Off}$ states, respectively.

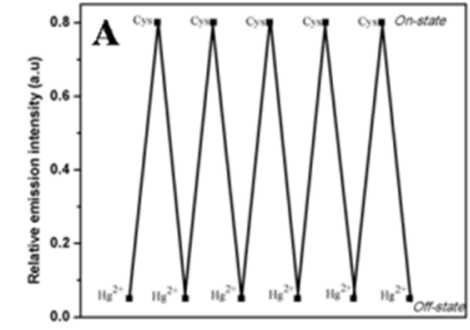

B

\begin{tabular}{|c|c|c|}
\hline $\begin{array}{c}\text { Rest (Input 1, } \\
\text { Hg') }\end{array}$ & $\begin{array}{c}\text { Set (Input 2, } \\
\text { Cys ) }\end{array}$ & Output \\
\hline 0 & 0 & 1 \\
\hline 1 & 0 & 0 \\
\hline 0 & 1 & 1 \\
\hline 1 & 1 & 1 \\
\hline
\end{tabular}

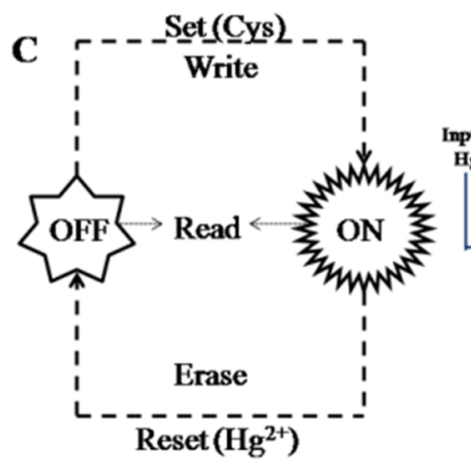

D

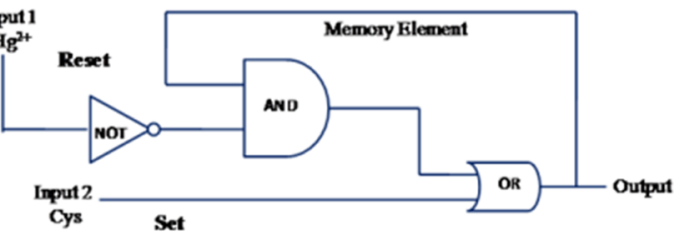

Figure 10. (A) Reversibility of the $\mathrm{CD}$ probe with alternate addition of $\mathrm{Hg}^{2+}$ and $\mathrm{L}-\mathrm{Cys}$, (B) truth table of the memory unit, (C) the feedback loops with Write-Read-Erase-Read function, (D) the sequential logic circuit of the memory unit.

and IMP gates, by utilizing CDs as probe and $\mathrm{Hg}^{2+}$ and L-Cys as chemical inputs. $^{22 a}$ The fluorescence intensity change at $435 \mathrm{~nm}$ was fixed as the output signal. The output signal is considered as "On" state with a Boolean arithmetic value of " 1 " with the original or initial value of the emission intensity and considered as "Off" state with Boolean arithmetic value of " 0 " when the emission is quenched by $50 \%$.

Interpretation of Logic Gate with Two Inputs. In a twoinput logic operation, $\mathrm{CD}$ operates as gate and analytes $\left(\mathrm{Hg}^{2+}, \mathrm{L}-\right.$ Cys) as the two chemical inputs (Figure 8). Boolean arithmetic expressions 0 and 1 were considered as inputs for the gate with and without of the analytes, correspondingly. ${ }^{22}$ Difference in the emission intensity at $435 \mathrm{~nm}$ of CD was considered as the output signal for analyzing On and Off states in the system. Different chemical inputs with four possible input string combinations $(0,0 ; 1,0 ; 0,1 ; 1,1)$ were carried out. Presence of the metal ion $\mathrm{Hg}^{2+}$ as input in the absence of its counter anion L-Cys, the system expressed NOT gate (Figure 8), the simplest of all logic gates. The quenching of the $\mathrm{CD}$ fluorescence is due to the formation of $\mathrm{CD}-\mathrm{Hg}^{2+}$ complex aided by the presence of oxygenous hydrophilic groups. These results corroborate with the NOT gate, i.e., Off state. Further, upon addition of the counter anion L-Cys (input 2), the fluorescence behavior was reversed, with almost $85 \%$ increase in the emission intensity (Figure 8 ). The high affinity of $\mathrm{Hg}^{2+}$ for the $-\mathrm{SH}$ group favors the formation of $\mathrm{Hg}^{2+}-\mathrm{L}-\mathrm{Cys}$ complex, which separates the metal ion from the hydrophilic groups on the surface of $\mathrm{CD}$, thereby recovering the fluorescence of CDs. Thus, an IMP gate has been constructed by using $\mathrm{Hg}^{2+}$ and L-Cys as inputs 1 and 2, respectively. The presence of both inputs 1 and 2 in the system expressed an On state. This clearly confirms that the decreased emission intensity in $\mathrm{CD}-\mathrm{Hg}^{2+}$ is recovered by the stable $\mathrm{Hg}^{2+}-$ L-Cys complex formation. The truth table also confirms the IMP gate (Figure 8) behavior. The overall gate functions are represented in the Scheme 1. Thus, this CD nano-chemosensor can be used as a chemical logic gate for identification of mercury in real samples via fluorescent switching behavior pattern.

Security Lock Device. The keypad lock development is interesting because a new approach for protecting information at a molecular level and has been utilized for various sensitive restricted data applications. ${ }^{23}$ We have tried the utility of this system in electronic security devices, with the idea of a switching 
behavior in the present CD system (Figure 9). We checked the difference in the emission behavior in a keypad security lock system (Figure 9). The utility of CD is as a probe in a security keypad sensing device for $\mathrm{Hg}^{2+}$; fluorescent probe $\mathrm{CD}$ was subjected to the chemical inputs $\left(\mathrm{Hg}^{2+}, \mathrm{L}-\mathrm{Cys}\right)$ either separately or in combination with $\mathrm{CD}\left(\mathrm{CD}-\mathrm{Hg}^{2+}, \mathrm{CD}-\mathrm{L}-\mathrm{Cys}\right)$. The molecular thiol in $\mathrm{L}-\mathrm{Cys}$ will form a strong $\mathrm{Hg}^{2+}-\mathrm{SH}$ bond, resulting in desorption of $\mathrm{Hg}^{2+}$ from $\mathrm{CD}$ surface, leading to a "Off-On" behavior. Thus, while operating, if we first add L-Cys to the system containing $\mathrm{CD}-\mathrm{Hg}^{2+}$ (quenched state), the relative emission intensity will be close to that of $\mathrm{CD}$, i.e., fluorescence was almost recovered to $85 \%$, which implies On state, with respect to the probe $\mathrm{CD}$, whereas if we added $\mathrm{Hg}^{2+}$ to the system containing $\mathrm{CD}-\mathrm{L}-\mathrm{Cys}$ (already fluorescence), the fluorescence was almost the same (no change in fluorescence) with respect to $C D$, which denotes the Off state. Thus, with the change in the regulation of the inputs, the output signals (fluorescence) will be changed, enabling us to use the probe CD in a molecular keypad lock. The lock can be removed ("turn-On" state) using the order of inputs as $1 \rightarrow \mathrm{Hg}^{2+} \rightarrow \mathrm{L}$-Cys, whereas we can lock ("turn-Off" state) the device using the order of inputs as $1 \rightarrow \mathrm{L}-\mathrm{Cys} \rightarrow \mathrm{Hg}^{2+}$.

To demonstrate the security lock device in terms of crossword puzzles, the analytes used as chemical inputs were named as $\mathrm{H}$ and $\mathrm{C}$ for $\mathrm{Hg}^{2+}$ and L-cysteine, respectively, and the fluorescence emission was considered as the output signal. The symbols $\mathrm{O}$ and $\mathrm{F}$ were noted for $\mathrm{On}$ and Off states. While executing the password, pressing $\mathrm{C}$ followed by $\mathrm{H}$, the emission output will turn the switch on $(\mathrm{O})$, i.e. turn-On state. However, pressing $\mathrm{H}$ and then $\mathrm{C}$ will cause no change in the output emission; the device remains locked, i.e., turn-Off state $(F)$. Thus, the password "HCF" will lock the device whereas the password "CHO" opens the lock without fail.

Memory Device. This system can be used as a memory element, in molecular-level information processing for its unique switching nature: reversible response with alternate addition of $\mathrm{Hg}^{2+}$ and L-Cys (Figure 10). Generally, sequential circuits in memory devices store the information and operate through a response loop, where one output in the logic system serves as a memory element. ${ }^{24}$ For mimicking the memory element, we have used the chemical input $\mathrm{Hg}^{2+}$ (input 1) and Cys (input 2) as Reset (R) and Set (S), respectively. The emission intensity is taken as the output signal (Figure 10). When the reset input (input 1) shows a quenching effect, i.e., low emission, the system is considered in "Off-state", where the system "Read" the information, "Erase" it, and saves the "output" as 0 . The above stored information, in other words, memorized information, was considered as "Write" by set input (input 2) and saves the output as 1 . This "Write-Erase" cycle on CD probe can be performed for multiple cycles by adding $\mathrm{Hg}^{2+}$ and Cys in alternate sequence. This Off-On reversible behavior using chemical analytes represents the "Write-Read-Erase-Read" nature (Figure 10). Thus, this system can be used as molecular microprocessors, a substitute for the traditional memory element in integrated logic circuits. To test and ensure the practical applications of the carbon dots to sense $\mathrm{Hg}(\mathrm{II})$ in water samples (lake and tap water), standard recovery experiments were performed. The water samples were added with different known quantities of $\mathrm{Hg}^{2+}$ and L-cysteine to compare and to imitate the realenvironment measurements. It is apparent that the carbon dotbased $\mathrm{Hg}(\mathrm{II})$ chemosensor system is reliable and valid for detecting $\mathrm{Hg}^{2+}$ in water samples (Table S2, Supporting Information).

\section{CONCLUSIONS}

In summary, we have presented a simple, low-cost, direct, and green one-pot method to produce CDs from the pineapple waste (peel) without any oxidizing agents through hydrothermal treatment. The CDs in aqueous solution emit strong blue light under a UV lamp with a fluorescent quantum yield of 0.42 . This CD-based sensing system shows an ultraselective and sensitive fluorescent probe for label-free $\mathrm{Hg}^{2+}$ ion detection and has been successfully used for visual identification and quantitation of $\mathrm{Hg}^{2+}$ in real water samples from lake and tap water with satisfactory results. Further studies showed that the CDs can be used as a fluorescent probe for cellular imaging of $\mathrm{Hg}^{2+}$. The CDs exhibited multiple logic gates and were capable of mimicking a security keypad lock device at the molecular level with chemical inputs of $\mathrm{Hg}^{2+}$ ion and L-Cys. The CDs have also been used as molecular microprocessors, an alternative for the traditional memory element in integrated logic circuits.

\section{EXPERIMENTAL SECTION}

Synthesis of Carbon Dots. CDs were prepared from pineapple peel by hydrothermal method similar to the procedure used by us. ${ }^{21 a}$ In a typical procedure, the peel of pineapple was rinsed many times with water to remove the filth particles and was made into juice. Ten milliliters of the extract and $10 \mathrm{~mL}$ of ethanol were taken, and the reaction was preceded in an autoclave at $150{ }^{\circ} \mathrm{C}$ for $2 \mathrm{~h}$, followed by extraction with methylene chloride and dialysis through a cellulose dialysis membrane. The aqueous solution was centrifuged at $10000 \mathrm{rpm}$ for $15 \mathrm{~min}$ to separate the less-fluorescent deposit. Excess acetone was added in the upper brown solution and centrifuged at high speed $(15000 \mathrm{rpm})$ for $15 \mathrm{~min}$ to obtain highly fluorescent CDs of average size 3-4 nm. As-obtained CDs were lyophilized and redispersed in water $\left(1 \mathrm{mg} \mathrm{mL}^{-1}\right)$ for further use.

\section{ASSOCIATED CONTENT}

\section{S Supporting Information}

The Supporting Information is available free of charge on the ACS Publications website at DOI: 10.1021/acsomega.8b01146.

Instrumentation details, quantum yield calculation, effect of ionic strength on fluorescence, bar diagram representation of the fluorescence response over metal ions, and comparison table (PDF)

\section{AUTHOR INFORMATION}

\section{Corresponding Authors}

*E-mail: raman474@gmail.com (G.S.).

*E-mail: vesp1984@gmail.com (S.S.).

*E-mail: bvnathan@iitm.ac.in (B.V.).

ORCID

Gandhi Sivaraman: 0000-0002-6919-9658

Subramanian Singaravadivel: 0000-0001-5554-8522

Notes

The authors declare no competing financial interest.

\section{ACKNOWLEDGMENTS}

We acknowledge the Department of Science and Technology (DST), India, for funding National Centre for Catalysis Research (NCCR), Indian Institute of Technology Madras (IITM). S.S. thanks the DST-SERB Early Career Research Award for financial support (No. ECR/2017/000380/CS). 


\section{REFERENCES}

(1) (a) Baptista, F. R.; Belhout, S. A.; Giordani, S.; Quinn, S. J. Recent developments in carbon nanomaterial sensors. Chem. Soc. Rev. 2015, 44, 4433-4453. (b) Dong, Y.; Pang, H.; Yang, H. B.; Guo, C.; Shao, J.; Chi, Y.; Li, C. M.; Yu, T. Carbon-Based Dots Co-doped with Nitrogen and Sulfur for High Quantum Yield and Excitation-Independent Emission. Angew. Chem., Int. Ed. 2013, 52, 7800-7804. (c) Liu, H.; Ye, T.; Mao, C. Fluorescent carbon nanoparticles derived from candle soot. Angew. Chem., Int. Ed. 2007, 46, 6473-6475. (d) Baker, S. N.; Baker, G. A. Luminescent Carbon Nanodots: Emergent Nanolights. Angew. Chem., Int. Ed. 2010, 49, 6726-6744.

(2) (a) Li, H.; Kang, Z.; Liu, Y.; Lee, S.-T. Carbon nanodots: synthesis, properties and applications. J. Mater. Chem. 2012, 22, 24230-24253. (b) Gao, X.; Du, C.; Zhuang, Z.; Chen, W. Carbon quantum dot-based nanoprobes for metal ion detection. J. Mater. Chem. C 2016, 4, 69276945. (c) Wang, F.; Xie, Z.; Zhang, H.; Liu, C. Y.; Zhang, Y. G. Highly Luminescent Organosilane-Functionalized Carbon Dots. Adv. Funct. Mater. 2011, 21, 1027-1031. (d) Yu, C.; Li, X. Z.; Zeng, F.; Zheng, F. Y.; Wu, S. Z. Carbon-dot-based ratiometric fluorescent sensor for detecting hydrogen sulfide in aqueous media and inside live cells. Chem. Commun. 2013, 49, 403-405. (e) Tao, H.; Yang, K.; Ma, Z.; Wan, J.; Zhang, Y.; Kang, Z.; Liu, Z. In Vivo NIR Fluorescence Imaging, Biodistribution, and Toxicology of Photoluminescent Carbon Dots Produced from Carbon Nanotubes and Graphite. Small 2012, 8, 281290. (f) Lai, C.-W.; Hsiao, Y.-H.; Peng, Y.-K.; Chou, P.-T. Facile synthesis of highly emissive carbon dots from pyrolysis of glycerol; gram scale production of carbon dots $/ \mathrm{mSiO}_{2}$ for cell imaging and drug release. J. Mater. Chem. 2012, 22, 14403-14409.

(3) (a) Wang, Z. X.; Zheng, C. L.; Li, Q. L.; Ding, S. N. Electrochemiluminescence of a nano Ag-carbon nanodot composite and its application to detect sulfide ions. Analyst 2014, 139, 1751-1755. (b) Shen, L.; Chen, M.; Hu, L.; Chen, X.; Wang, J. Growth and Stabilization of Silver Nanoparticles on Carbon Dots and Sensing Application. Langmuir 2013, 29, 16135-16140. (c) Chen, P. C.; Chen, Y. N.; Hsu, P. C.; Shih, C. C.; Chang, H. T. Photoluminescent organosilane-functionalized carbon dots as temperature probes. Chem. Commun. 2013, 49, 1639-1641.

(4) (a) Zheng, M.; Liu, S.; Li, J.; Qu, D.; Zhao, H.; Guan, X.; Hu, X.; Xie, Z.; Jing, X.; Sun, Z. Integrating Oxaliplatin with Highly Luminescent Carbon Dots: An Unprecedented Theranostic Agent for Personalized Medicine. Adv. Mater. 2014, 26, 3554-3560. (b) Tang, J.; Kong, B.; Wu, K. H.; Xu, M.; Wang, Y.; Wang, Y.; Zhao, D.; Zheng, G. Carbon Nanodots Featuring Efficient FRET for Real-Time Monitoring of Drug Delivery and Two-Photon Imaging. Adv. Mater. 2013, 25, 6569-6574.

(5) Li, H.; He, X.; Kang, Z.; Huang, H.; Liu, Y.; Liu, J.; Lian, S.; Tsang, C. H.; Yang, X.; Lee, S. T. Water-Soluble Fluorescent Carbon Quantum Dots and Photocatalyst Design. Angew. Chem. 2010, 122, 4532-4536. (6) (a) Tu, X.; Ma, Y.; Cao, Y.; Huang, J.; Zhang, M.; Zhang, Z. PEGylated carbon nanoparticles for efficient in vitro photothermal cancer therapy. J. Mater. Chem. B 2014, 2, 2184-2212. (b) Bhunia, S. K.; Saha, A.; Maity, A. R.; Ray, S. C.; Jana, N. R. Carbon nanoparticlebased fluorescent bioimaging probes. Sci. Rep. 2013, 3, No. 1473. (c) Tetsuka, H.; Asahi, R.; Nagoya, A.; Okamoto, K.; Tajima, I.; Ohta, R.; Okamoto, A. Optically Tunable Amino-Functionalized Graphene Quantum Dots. Adv. Mater. 2012, 24, 5333-5338.

(7) (a) Shi, W.; Wang, Q.; Long, Y.; Cheng, Z.; Chen, S.; Zhen, H.; Huang, Y. Carbon nanodots as peroxidase mimetics and their applications to glucose detection. Chem. Commun. 2011, 47, 66956697. (b) Shen, C.; Sun, Y.; Wang, J.; Lu, Y. Facile route to highly photoluminescent carbon nanodots for ion detection, $\mathrm{pH}$ sensors and bioimaging. Nanoscale 2014, 6, 9139-9174. (c) Qu, S.; Wang, X.; Lu, Q.; Liu, X.; Wang, L. A Biocompatible Fluorescent Ink Based on WaterSoluble Luminescent Carbon Nanodots. Angew. Chem., Int. Ed. 2012, 51, 12215-12218. (d) Urakami, H.; Antonietti, M.; Vilela, F. Facile functionalization of HTC-derived carbon microspheres. Chem. Commun. 2012, 48, 10984-10986. (e) Chowdhury, D.; Gogoi, N.; Majumdar, G. Fluorescent carbon dots obtained from chitosan gel. RSC Adv. 2012, 2, 12156-12159. (f) Costas-Mora, I.; Romero, V.; Lavilla,
I.; Bendicho, C. In Situ Building of a Nanoprobe Based on Fluorescent Carbon Dots for Methylmercury Detection. Anal. Chem. 2014, 86, 4536-4543. (g) Sun, Y.-P.; Zhou, B.; Lin, Y.; Wang, W.; Fernando, K. S.; Pathak, P.; Meziani, M. J.; Harruff, B. A.; Wang, X.; Wang, H.; et al. Quantum-Sized Carbon Dots for Bright and Colorful Photoluminescence. J. Am. Chem. Soc. 2006, 128, 7756-7757.

(8) (a) Xie, Z.; Wang, F.; Liu, C. Organic-Inorganic Hybrid Functional Carbon Dot Gel Glasses. Adv. Mater. 2012, 24, 17161721. (b) Zheng, M.; Xie, Z.; Qu, D.; Li, D.; Du, P.; Jing, X.; Sun, Z. OnOff-On Fluorescent Carbon Dot Nanosensor for Recognition of Chromium(VI) and Ascorbic Acid Based on the Inner Filter Effect. ACS Appl. Mater. Interfaces. 2013, 5, 13242-13247. (c) Wang, J.; Wang, C.; Chen, S. Amphiphilic egg-derived carbon dots: rapid plasma fabrication, pyrolysis process, and multicolor printing patterns. Angew. Chem., Int. Ed. 2012, 51, 9297-9301. (d) Sahu, S.; Behera, B.; Maitib, T. K.; Mohapatra, S. Simple one-step synthesis of highly luminescent carbon dots from orange juice: application as excellent bio-imaging agents. Chem. Commun. 2012, 48, 8835-8837. (e) Zhao, S.; Lan, M.; Zhu, X.; Xue, H.; Ng, T.-W.; Meng, X.; Lee, C.-S.; Wang, P.; Zhang, W. Green Synthesis of Bifunctional Fluorescent Carbon Dots from Garlic for Cellular Imaging and Free Radical Scavenging. ACS Appl. Mater. Interfaces 2015, 7, 17054-17060.

(9) (a) Wen, X.; Shi, L.; Wen, G.; Li, Y.; Dong, C.; Yang, J.; Shuang, S. Green synthesis of carbon nanodots from cotton for multicolor imaging, patterning, and sensing. Sens. Actuators, B 2015, 221, 769776. (b) Yu, C.; Xuan, T.; Chen, Y.; Zhao, Z.; Sun, Z.; Li, H. A facile, green synthesis of highly fluorescent carbon nanoparticles from oatmeal for cell imaging. J. Mater. Chem. C 2015, 3, 9514-9518. (c) Sachdev, A.; Gopinath, P. Green synthesis of multifunctional carbon dots from coriander leaves and their potential application as antioxidants, sensors and bioimaging agents. Analyst 2015, 140, 4260-4269. (d) Choi, Y.; Kim, S.; Choi, M.-H.; Ryoo, S.-R.; Park, J.; Min, D.-H.; Kim, B.-S. Highly Biocompatible Carbon Nanodots for Simultaneous Bioimaging and Targeted Photodynamic Therapy In Vitro and In Vivo. Adv. Funct. Mater. 2014, 24, 5781-5789. (e) Kong, L.; Wang, C.; et al. Biocompatible Glutathione Capped Functionalized Carbon Dots as Nanosensors for the Detection of Silver Nanoparticles in Aqueous Solution and Human Cells as well as Bacterial Cells. ChemistrySelect 2016, 1, 4092-4100.

(10) (a) Bandi, R.; Gangapuram, B. R.; Dadigala, R.; Eslavath, R.; Singh, S. S.; Guttena, V. Facile and green synthesis of fluorescent carbon dots from onion waste and their potential applications as sensor and multicolour imaging agents. RSC Adv. 2016, 6, 28633-28639. (b) Huang, H.; Xu, Y.; Tang, C.-J.; Chen, J.-R.; Wang, A.-J.; Feng, J.$\mathrm{J}$. Facile and green synthesis of photoluminescent carbon nanoparticles for cellular imaging. New J. Chem. 2014, 38, 784-789. (c) Mehta, V. N.; Jha, S.; Basu, H.; Singhal, R. K.; Kailas, S. K. One-step hydrothermal approach to fabricate carbon dots from apple juice for imaging of mycobacterium and fungal cells. Sens. Actuators, B 2015, 213, 434-443. (d) Wang, L.; Zhou, H. S. Green Synthesis of Luminescent NitrogenDoped Carbon Dots from Milk and Its Imaging Application. Anal. Chem. 2014, 86, 8902-8906. (e) Rani, B. K.; Abraham John, S. A novel pyrene based fluorescent probe for selective detection of cysteine in presence of other biothiols in living cells. Biosens. Bioelectron. 2016, 83, 237-242.

(11) (a) Liu, W.; Diao, H.; Changa, H.; Wang, H.; Li, T.; Wei, W. Green synthesis of carbon dots from rose-heart radish and application for $\mathrm{Fe}^{3+}$ detection and cell imaging. Sens. Actuators, B 2017, 241, 190198. (b) De, B.; Karak, N. A green and facile approach for the synthesis of water soluble fluorescent carbon dots from banana juice. RSC Adv. 2013, 3, 8286-8290.

(12) (a) Cao, L.; Wang, X.; Meziani, M. J.; Lu, F.; Wang, H.; Luo, P. G.; Lin, Y.; Harruff, B. A.; Veca, L.; M. Murray, D.; Xie, S.-Y.; Sun, Y.-P. Carbon Dots for Multiphoton Bioimaging. J. Am. Chem. Soc. 2007, 129, 11318-11319. (b) Hu, Y.; Zhang, L.; Li, X.; Liu, R.; Lin, L.; Zhao, S. Green Preparation of $S$ and N Co-Doped Carbon Dots from Water Chestnut and Onion as Well as Their Use as an Off-On Fluorescent Probe for the Quantification and Imaging of Coenzyme A. ACS Sustainable Chem. Eng. 2017, 5, 4992-5000. 
(13) (a) Wan, J.; Guo, J.; Miao, Z.; Guo, X. Reverse micellar extraction of bromelain from pineapple peel-Effect of surfactant structure. Food Chem. 2016, 197, 450-456. (b) Hu, X.; Hu, K.; Zeng, L.; Zhao, M.; Huang, H. Hydrogels prepared from pineapple peel cellulose using ionic liquid and their characterization and primary sodium salicylate release study. Carbohydr. Polym. 2010, 82, 62-68. (c) Esti, M.; Benucci, I.; Liburdi, K.; Garzillo, A. M. Effect of Wine Inhibitors on Free Pineapple Stem Bromelain Activity in a Model Wine System. J. Agric. Food Chem. 2011, 59, 3391-3397.

(14) (a) Hu, X.; Wang, J.; Huang, H. Impacts of some macromolecules on the characteristics of hydrogels prepared from pineapple peel cellulose using ionic liquid. Cellulose 2013, 20, 2923-2933. (b) Rattanapoltee, P.; Kaewkannetra, P. Utilization of agricultural residues of pineapple peels and sugarcane bagasse as cost-saving raw materials in Scenedesmus acutus for lipid accumulation and biodiesel production. Appl. Biochem. Biotechnol. 2014, 173, 1495-1510.

(15) (a) Lu, W.; Qin, X.; Liu, S.; Chang, G.; Zhang, Y.; Luo, Y.; Asiri, A. M.; Al-Youbi, A. O.; Sun, X. Economical, Green Synthesis of Fluorescent Carbon Nanoparticles and Their Use as Probes for Sensitive and Selective Detection of Mercury(II) Ions. Anal. Chem. 2012, 84, 5351-5357. (b) Zhou, L.; Lin, Y.; Huang, Z.; Ren, J.; Qu, X. Carbon nanodots as fluorescence probes for rapid, sensitive, and labelfree detection of $\mathrm{Hg}^{2+}$ and biothiols in complex matrices. Chem. Commun. 2012, 48, 1147-1149. (c) Long, Y. J.; Li, Y. F.; Liu, Y.; Zheng, J. J.; Tang, J.; Huang, C. Z. Visual observation of the mercurystimulated peroxidase mimetic activity of gold nanoparticles. Chem. Commun. 2011, 47, 11939-11941.

(16) Tchounwou, P. B.; Ayensu, W. K.; Ninashvili, N.; Sutton, D. Environmental exposure to mercury and its toxicopathologic implications for public health. Environ. Toxicol. 2003, 18, 149-175.

(17) (a) Li, L.; Yu, B.; You, T. Nitrogen and sulfur co-doped carbon dots for highly selective and sensitive detection of $\mathrm{Hg}$ (II) ions. Biosens. Bioelectron. 2015, 74, 263-269. (b) Yan, F.; Shi, D.; Zheng, T.; Yun, K.; Zhou, X.; Chen, L. Carbon dots as nanosensor for sensitive and selective detection of $\mathrm{Hg}^{2+}$ and L-Cysteine by means of fluorescence "Off-On" switching. Sens. Actuators, B 2016, 224, 926-935. (c) Liu, J.; Chen, Y.; Wang, W.; Feng, J.; Peng, S.; Ma, S.; Chen, H.; Chen, X. Effective synthesis of highly fluorescent nitrogen doped carbon nanoparticles for selective sensing of $\mathrm{Hg}^{2+}$ in food and cosmetics samples. RSC $A d v$. 2016, 6, 89916-89924. (d) Feng, H.; Qian, Z. Functional Carbon Quantum Dots: A Versatile Platform for Chemosensing and Biosensing. Chem. Rec. 2018, 18, 491-505. (e) Tang, C.; Feng, H.; Qian, Z.; Huang, Y. Reversible Luminescent Nanoswitches Based on Aggregation-Induced Emission Enhancement of Silver Nanoclusters for Luminescence Turn-on Assay of Inorganic Pyrophosphatase Activity. Anal. Chem. 8949945002. DOI: 10.1021/acs.analchem.7b00319. (f) Huang, Y.; Zhou, J.; Feng, H.; Zheng, J.; et al. A dual-channel fluorescent chemosensor for discriminative detection of glutathione based on functionalized carbon quantum dots. Biosens. Bioelectron. 2016, 86, 748-752.

(18) Miao, P.; Han, K.; Tang, Y.; Wang, B.; Lin, T.; Cheng, W. Recent advances in carbon nanodots: synthesis, properties and biomedical applications. Nanoscale 2015, 7, 1586-1595.

(19) (a) Dhenadhayalan, N.; Lin, K.-C.; Suresh, R.; Ramamurthy, P. Unravelling the Multiple Emissive States in Citric-Acid-Derived Carbon Dots. J. Phys. Chem. C 2016, 120, 1252-1261. (b) Choudhury, S. D.; Chethodil, J. M.; Gharat, P. M.; Praseetha, P. K.; Pal, H. pHElicited Luminescence Functionalities of Carbon Dots: Mechanistic Insights. J. Phys. Chem. Lett. 2017, 8, 1389-1395.

(20) Pooja, D.; Saini, S.; Thakur, A.; Kumar, B.; Tyagi, S.; Nayak, M. K. A "Turn-On" thiol functionalized fluorescent carbon quantum dot based chemosensory system for arsenite detection. J. Hazard. Mater. 2017, 328, 117-126.

(21) (a) Vandarkuzhali, S. A. A.; Jeyalakshmi, V.; Sivaraman, G.; Singaravadivel, S.; Krishnamurthy, K. R.; Viswanathan, B. Highly fluorescent carbon dots from Pseudo-stem of banana plant: Applications as nanosensor and bio-imaging agents. Sens. Actuators, $B$ 2017, 252, 894-900. (b) Song, Y.; Zhu, S.; Xiang, S.; Zhao, X.; Zhang, J.; Zhang, H.; Fua, Y.; Yang, B. Investigation into the fluorescence quenching behaviors and applications of carbon dots. Nanoscale 2014, 6, 4676-4682. (c) Zhu, S.; Meng, Q.; Wang, L.; Zhang, J.; Song, Y.; Jin, H.; Zhang, K.; Sun, H.; Wang, H.; Yang, B. Highly Photoluminescent Carbon Dots for Multicolor Patterning, Sensors, and Bioimaging. Angew. Chem., Int. Ed. 2013, 52, 3953-3957.

(22) (a) Dhenadhayalan, N.; Lin, K.-C. Chemically Induced Fluorescence Switching of Carbon-Dots and Its Multiple Logic Gate Implementation. Sci. Rep. 2015, 5, No. 10012. (b) Meng, F.; Hervault, Y. M.; Shao, Q.; Hu, B.; Norel, L.; Rigaut, S.; Chen, X. Orthogonally modulated molecular transport junctions for resettable electronic logic gates. Nat. Commun. 2014, 5, No. 3023.

(23) Misra, A.; Srivastava, P.; Shahid, M. Fluorescent probe mimicking multiple logic gates and a molecular keypad lock upon interaction with $\mathrm{Hg}^{2+}$ and bovine serum albumin. Analyst 2012, 137, 3470-3478.

(24) Razi, S. S.; Srivastava, P.; Ali, R.; Gupta, R. C.; Dwivedi, S. K.; Misra, A. A. A coumarin-derived useful scaffold exhibiting $\mathrm{Cu}^{2+}$ induced fluorescence quenching and fluoride sensing (On-Off-On) via copper displacement approach. Sens. Actuators, B 2015, 209, 162-171. 